\title{
Nota e espécies novas de Cyrtinus LeConte (Coleoptera, Cerambycidae, Lamiinae, Cyrtinini) da Região Neotropical
}

\author{
Ubirajara R. Martins ${ }^{1,3} \&$ Maria Helena M. Galileo ${ }^{2,3}$
}

${ }^{1}$ Museu de Zoologia, Universidade de São Paulo. Caixa Postal 42494, 04218-970 São Paulo-SP, Brasil. urmsouza@ usp.br
${ }^{2}$ Museu de Ciências Naturais, Fundação Zoobotânica do Rio Grande do Sul. Caixa Postal 1188, 90001-970 Porto Alegre-RS, Brasil.
galileo@ fzb.rs.gov.br
${ }^{3}$ Pesquisador do CNPq.

\begin{abstract}
Notes and new species of Cyrtinus LeConte, 1852 (Coleoptera, Cerambycidae, Lamiinae, Cyrtinini) from the Neotropical region. New species are described of Cyrtinus LeConte, 1852: C. hispidus sp. nov. from Ecuador (Pichincha); C. bifasciatus sp. nov. from Panama (Colon) and from Costa Rica, C. umbus sp. nov. (Guanacaste) and $C$. melzeri sp. nov. (Cartago). Occurrence and illustration of C. penicillatus (Bates, 1885) are added.
\end{abstract}

KEYWORDS. Cyrtinus; new species; taxonomy.

RESUMO. Nota e espécies novas de Cyrtinus LeConte (Coleoptera, Cerambycidae, Lamiinae, Cyrtinini) da Região Neotropical. São descritas novas espécies de Cyrtinus LeConte, 1852: C. hispidus sp. nov. do Equador (Pichincha); $C$. bifasciatus sp. nov. do Panamá (Colón) e da Costa Rica, C. umbus sp. nov. (Guanacaste) e C. melzeri sp. nov. (Cartago). Acrescentam-se ocorrência e figura de C. penicillatus (Bates, 1885)

PALAVRAS-CHAVE. Cyrtinus; novas espécies; taxonomia.

O gênero Cyrtinus LeConte, 1852 encerra espécies muito pequenas, com comprimento médio de 2,0 a $4,0 \mathrm{~mm}$, que ocorrem na América do Norte (Estados Unidos, México), na América Central Insular (Cuba, Jamaica, Haiti, Porto Rico, Pequenas Antilhas), América Central Continental (Honduras, Costa Rica, Panamá) e norte da América do Sul (Venezuela, Equador). Contam-se 22 espécies na lista remissiva de Monné \& Hovore (2006).

Howden dedicou vários artigos aos Cyrtinus. Em 1959, descreveu duas espécies e apresentou chave para as espécies de Cyrtinus do Novo Mundo. Em 1960, acrescentou mais duas espécies. Em 1970, cuidou dos Cyrtinus da Jamaica, descreveu outras duas espécies e apresentou chave para sua identificação. Em 1973, descreveu duas espécies uma do México e uma da Venezuela, assinalando assim o gênero para a América do Sul.

Zayas (1975) acrescentou ao gênero uma espécie de Cuba. Joly \& Rosales (1990) descreveram mais três espécies da Venezuela.

Incorporamos ao gênero neste trabalho mais quatro espécies, duas da Costa Rica, uma do Panamá e uma do Equador, esta a procedência mais meridional para Cyrtinus.

O material estudado pertence às instituições: ACMT, American Coleoptera Museum, San Antonio; LBSC, Coleção Larry G. Bezark, Sacramento; MZSP, Museu de Zoologia, Universidade de São Paulo, São Paulo.

\section{Cyrtinus penicillatus (Bates, 1885)}

(Fig. 1)

Myrmolamia penicillata Bates, 1885: 364.

Cyrtinus penicillatus; Aurivillius, 1923: 450; Monné, 2005: 371 (cat.).
Material examinado. PANAMÁ, Colón: Fort Sherman $\left(9^{\circ} 17^{\prime} \mathrm{N}\right.$ 59 59'W), 10.III.2001, F. Odegaard col. "on Marila laxifolia", 3 exs., 20.III.2001, F. Odegaard col. (ACMT, 1 retido MZSP).

\section{Cyrtinus melzeri sp. nov.}

(Fig. 2)

Etimologia. Epíteto em homenagem póstuma ao entomólogo Julius Melzer pela contribuição ao conhecimento dos Cerambycidae.

Cabeça preto-avermelhada; esparsamente pontuada. Vértice liso. Região entre os tubérculos anteníferos com alguns pontos finos. Escapo gradualmente engrossado para o ápice. Antenômeros com a base alaranjada e o ápice preto. Escapo subigual em comprimento a soma dos antenômeros II e III; comprimentos dos antenômeros III-XI subiguais.

Protórax com constrição basal acentuada; partes laterais brilhantes. Pronoto liso; uma fileira transversal de pêlos escamiformes, brancos, próximos à base. Lados do metasterno com pontos muito finos.

Élitros com o terço basal avermelhado e os dois terços basais pretos. Cada élitro com bossa centro-basal projetada e encimada por pontos; uma faixa estreita de pêlos escamiformes, brancos, oblíqua no sentido descendente da sutura para a margem, situada no terço anterior.

Pro- e mesofêmures avermelhados. Metafêmures com pedúnculo avermelhado e clava castanho-avermelhada.

Urosternitos, látero-posteriormente, com alguns pêlos brancos.

Dimensões em mm, holótipo e parátipo, respectivamente. Comprimento total, 2,5-3,1; comprimento do protórax, 0,7-0,9; maior largura do protórax, 0,5-0,7; largura da constrição basal 
do protórax, 0,4-0,6; comprimento do élitro, 1,6-2,0; largura umeral, $0,7-0,8$.

Material-tipo. Holótipo, COSTA RICA, Cartago: Turrialba, IX.1928, Schilde col., ex-Col. Melzer (MZSP); parátipo, mesmos dados do holótipo (MZSP).

Discussão. Melzer identificou os espécimes como " $C$. penicillatus var. Bates". Na realidade, Cyrtinus melzeri sp. nov. assemelha-se a C. penicillatus (Bates, 1885) e difere pela região anterior dos élitros avermelhada e pela faixa de pêlos brancos nos élitros oblíqua. Em C. penicillatus os élitros são pretos e a faixa de pêlos brancos é transversal à sutura.

Cyrtinus melzeri sp. nov. difere de Cyrtinus umbus sp. nov. pela presença de faixa de pêlos escamiformes, brancos, na base do pronoto, pelas antenas aneladas e pela gibosidade basal dos élitros muito projetada e encimada por pontos. Em C. umbus sp. nov. a base do pronoto não tem fileira de pêlos escamiformes, as antenas não são aneladas e a base dos élitros têm bossa pouco projetada e lisa.

\section{Cyrtinus hispidus sp. nov.}

(Fig. 3)

Etimologia. Latim, hispidus = cabeludo; alusivo aos pêlos da crista centro-basal dos élitros.

Cabeça preta. Fronte esparsamente pontuada. Vértice com pontos finos, rasos e esparsos. Escapo pedunculado e fracamente clavado. Pedicelo e flagelômeros III-IX amarelados na base.

Protórax com a constrição basal bem acentuada. Pronoto preto-avermelhado com raros pontos (60X); uma faixa de pêlos escamiformes, brancos, interrompida no meio e junto à base. Partes laterais do protórax liso e brilhante.

Élitros pretos, brilhantes; crista centro-basal encimada por pêlos pretos; no terço anterior, uma faixa transversal pretoavermelhada; faixas de pêlos escamiformes, brancos, no terço anterior, oblíqua em sentido descendente da sutura para a margem. Pêlos mais isolados junto à sutura da faixa ao escutelo e numa linha oblíqua que se inicia próxima aos úmeros; mancha de pubescência branca, escamiforme, na declividade marginal no nível do quarto anterior.

Pro- e mesocoxas avermelhadas; fêmures com pedúnculo alaranjado e clava acastanhada. Esternos metatorácicos e urosternitos castanho-avermelhados, escurecido.

Dimensões em mm. Comprimento total, 3,0; comprimento do protórax, 0,8; maior largura do protórax 0,7; largura da constrição basal do protórax, 0,5 ; comprimento do élitro, 1,9; largura umeral, 0,9 .

Material-tipo. Holótipo macho, EQUADOR, Pichincha: Tandapi, 15.VI.1965, Peña col. (MZSP).

Discussão. Cyrtinus hispidus sp. nov. apresenta linha de setas rijas, eretas e brancas nas proximidades dos úmeros, caráter que não se encontra nas demais espécies. Separa-se de C. mussoi Joly \& Rosales, 1990, da Venezuela, além desse caráter, pela presença de crista centro-basal e pela ausência de faixa de pêlos finos na declividade apical dos élitros.

\section{Cyrtinus umbus sp. nov.}

(Fig. 4)

Etimologia. Latim, umbo = bossa; alusivo à crista centrobasal dos élitros.

Cabeça preto-avermelhada. Fronte pontuada. Vértice esparsamente pontuado com alguns pêlos. Escapo curvo, esbelto, pouco engrossado para o ápice. Pedicelo e antenômeros III-VII alaranjados, VIII alaranjado na base e preto na metade apical, IX-XI pretos. Escapo subigual em comprimento a soma dos antenômeros II e III; comprimentos dos antenômeros III-XI subiguais.

Protórax com a constrição basal acentuada. Pronoto brilhante, praticamente liso. Escutelo com as bordas cobertas por pêlos brancos. Esternos mesotorácicos alaranjados e os metatorácicos, preto-acastanhados. Lados do metasterno com pêlos brancos.

Élitros com o terço anterior avermelhado e os dois terços apicais pretos; separa estas duas colorações, faixa de pêlos brancos, oblíqua em sentido descendente da sutura para a margem. Élitros com uma bossa lisa na base; alguns pontos próximos da sutura no quarto anterior.

Fêmures acastanhados com os pedúnculos amarelados. Tíbias acastanhadas.

Urosternitos gradualmente castanho-avermelhados a pretos em direção ao ápice.

Dimensões em mm, holótipo e parátipo. Comprimento total, 3,5-3,7; comprimento do protórax, 1,0-1,1; maior largura do protórax, 0,8-0,9; largura da constrição basal do protórax, 0,70,7; comprimento do élitro, 2,2-2,5; largura umeral, 0,9-1,0.

Material-tipo. Holótipo, COSTA RICA, Guanacaste: Rio Naranjo (3 km SE), 8-12.III.1992, F. D. Parker col. (LBSC). Parátipo, mesmos dados com data 4-8.I.1993 (MZSP).

Discussão. Cyrtinus umbus sp. nov. caracteriza-se pelo colorido das antenas e pela presença de bossa lisa na base dos élitros.

\section{Cyrtinus bifasciatus sp. nov.} (Fig. 5)

Etimologia. Latim, bi = dois; fasciatus = com faixa; referese às duas faixas de pêlos brancos nos élitros.

Fronte avermelhada. Vértice preto-avermelhado. Centro do vértice finamente pontuado com pêlos esparsos. Fronte e região entre os tubérculos anteníferos fina e densamente pontuadas. Escapo gradualmente engrossado para o ápice; avermelhado na base e preto no restante da superfície. Pedicelo avermelhado. Flagelômeros com a metade basal alaranjada e 

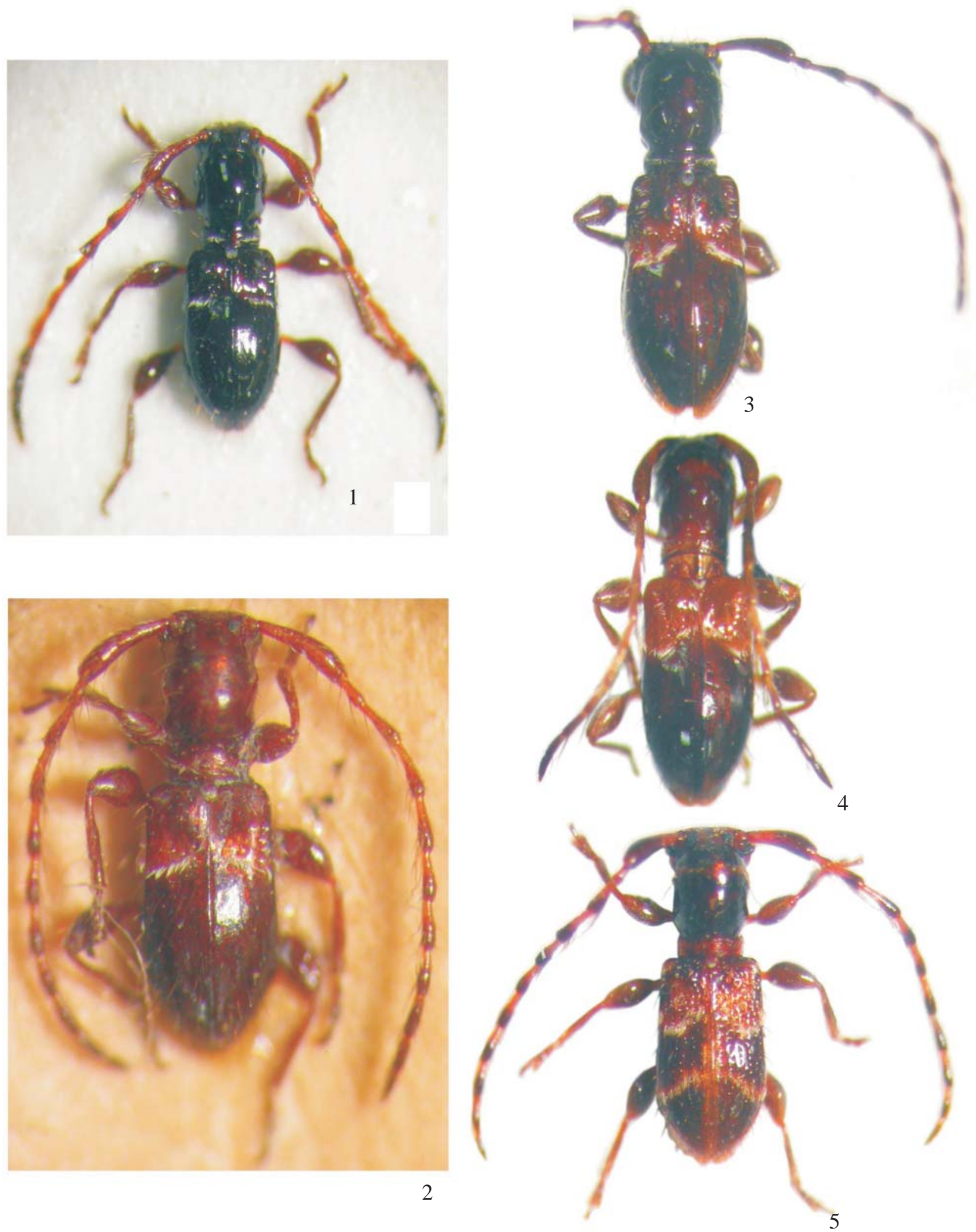

Figs. 1-5. 1, Cyrtinus penicillatus (Bates, 1885), comprimento 2,4 mm; 2, Cyrtinus melzeri sp. nov., holótipo, comprimento 2,5 mm; 3 , Cyrtinus hispidus sp. nov., holótipo, comprimento $3,0 \mathrm{~mm}$; 4, Cyrtinus umbus sp. nov., holótipo, comprimento 3,5 mm; 5, Cyrtinus bifasciatus sp. nov., holótipo, comprimento $2,8 \mathrm{~mm}$. 
metade apical preta. Escapo subigual em comprimento a soma dos antenômeros II e III; comprimentos dos antenômeros IIIXI subiguais.

Protórax com a constrição basal acentuada. Pronoto brilhante, com pontos muito esparsos.

Élitros pretos e alaranjados numa faixa transversal que quase ocupa todo o terço basal (menos a região circumescutelar) e no friso sutural. Pêlos escamiformes, brancos: numa faixa curva, ascendente para o lado da sutura e localizada no terço anterior; outra faixa, levemente oblíqua no terço apical; alguns pêlos esparsos entre a primeira faixa e a base. Região basal sem bossa; pontuação profunda na metade basal.

Fêmures acastanhados com pedúnculo amarelado. Tíbias e tarsos alaranjados.

Dimensões em mm, parátipo e holótipo. Comprimento total, 2,4-2,8; comprimento do protórax, 0,7-0,8; maior largura do protórax 0,6-0,7; largura da constrição basal do protórax, 0,50,5; comprimento do élitro, 1,4-1,7; largura umeral, 0,7-0,8.

Material-tipo. Holótipo, PANAMÁ, Colón: Fort Sherman $\left(9^{\circ} 17^{\prime} \mathrm{N}\right.$ $\left.59^{\circ} 59^{\prime} \mathrm{W}\right)$, 10.III.2001, F. Odegaard col. "on Symphonia globulifera"(ACMT); ditto, parátipo, 10.III.2001, F. Odegaard col. "on Symphonia globulifera"(MZSP).

Discussão. Cyrtinus bifasciatus sp. nov. distingue-se de C. penicillatus (Bates, 1885) (Fig. 1) pela ausência de faixa de pubescência na base do pronoto, pelo terço anterior dos élitros avermelhado e pelos élitros apresentarem duas faixas oblíquas de pêlos brancos. Em C. penicillatus a base do pronoto tem faixa de pubescência, os élitros têm o terço anterior quase preto e apresenta única faixa transversal de pêlos brancos.
Agradecimentos. A James Wappes (ACMT) e Larry Bezark (LBSC) pelo empréstimo de material. A Eleandro Moysés (Museu de Ciências Naturais, Fundação Zoobotânica do Rio Grande do Sul) pelas fotografias e tratamento das imagens.

\section{REFERÊNCIAS}

Aurivillius, C. 1923. Coleopterorum Catalogus, pars 74, Cerambycidae: Lamiinae II. Berlin, W. Junk. p. 323-704.

Bates, H. W. 1885. Biologia Centrali Americana, Insecta, Coleoptera, Supplement to Longicornia. London, v. 5, p. 249436.

Howden, H. F. 1959. Descriptions of two new species of Cyrtinus LeConte, with a key to the New World Cyrtinini (Coleoptera, Cerambycidae). The Canadian Entomologist 91: 373-375.

Howden, H. F. 1960. Two new species of Cyrtinus LeConte (Coleoptera, Cerambycidae). The Canadian Entomologist 92: 173-177.

Howden, H. F. 1970. Jamaican Cyrtinus, with descriptions of two new species (Coleoptera, Cerambycidae). The Canadian Entomologist 102: 1312-1316.

Howden, H. F. 1973. New species of Cyrtinus from Mexico and Venezuela (Coleoptera, Cerambycidae). The Canadian Entomologist, 105 595-597.

Joly, L. J. \& C. J. Rosales. 1990. Los Cyrtinini (Coleoptera, Cerambycidae, Lamiinae) de Venezuela. Boletín de Entomologia Venezolana 5: 205-211.

Monné, M. A. 2005. Catalogue of the Cerambycidae (Coleoptera) of the Neotropical Region. Part II. Subfamily Lamiinae. Zootaxa 1023: $1-759$.

Monné, M. A. \& Hovore, F. T. 2006. Checklist of the Cerambycidae, or longhorned wood-boring beetles, of the Western Hemisphere. Rancho Dominguez, BioQuip. 394 p.

Zayas, F. de. 1975. Revisión de la Família Cerambycidae (Coleoptera, Phytophagoidea). La Habana, Academia de Ciências de Cuba, 443 p.

Recebido em 24/07/2008; aceito em 05/10/2008 